\title{
Debriefing in simulation conducted in small and large groups - nursing students' experiences
}

\author{
Randi Tosterud $^{1,2}$, Marie Louise Hall-Lord ${ }^{1,2}$, Kerstin Petzäll2, Birgitta Hedelin ${ }^{2}$ \\ 1. Faculty of Health, Science and Technology, Department of Health Sciences, Karlstad University, Sweden. 2. Faculty of \\ Health, Care and Nursing, Department of Nursing, Gjøvik University College, Norway.
}

Correspondence: Randi Tosterud. Address: Teknologivn.22, N-2815 Gjøvik, Norway. Email: randi.tosterud@hig.no

Received: June 26, 2014

DOI : 10.5430/jnep.v4n9p173

\begin{abstract}
The debriefing phase in human patient simulation is considered to be crucial for learning. To ensure good learning conditions, the use of small groups is recommended, which poses a major challenge when the student count is high. The use of large groups may provide an alternative for typical lecture-style education and contribute to a more frequently and repeated training which is considered to be important for achieving simulation competency. The purpose of the present study was to describe nursing students' experiences obtained during the debriefing conducted in small and large groups with the use of a qualitative descriptive approach. The informants had participated in a human patient simulation situation either in large or small groups. Data was collected through the use of five focus-group interviews and analysed by content analysis. The findings showed that independent of group-size the informants experienced the learning strategies to be unfamiliar and intrusive, and in the large groups to such an extent that learning was hampered. Debriefing was perceived as offering excellent opportunities for transferable learning, and activity, predictability and preparedness were deemed essential. Small groups provided the best learning conditions in that safety and security were ensured, but were perceived as providing limited challenges to accommodate professional requirements as a nurse. Simulation competency as a prerequisite for learning was shown not to be developed isolated in conjunction with simulation, but depends on a systematic effort to build a learning community in the programme in general. The faculty needs to support the students to be conscious and accustomed to learning as a heightened experience of learning out of their comfort zone.
\end{abstract}

\section{Key words}

Human patient simulation, Debriefing, Nursing students’ experiences, Small and large groups

\section{I ntroduction}

The use of simulation as a pedagogical approach is widespread and rapidly expanding in nurse education ${ }^{[1,2]}$. Through the use of human patient simulation (HPS), realistic and holistic clinical situations can be recreated on campus ${ }^{[3]}$. The students are offered the options to learn, experience and practise nursing including the affective, cognitive and psychomotor domains, as well as an approach to team training as a prerequisite for enhancing patient safety ${ }^{[4,5]}$. Studies measuring student satisfaction show HPS to be successful ${ }^{[4]}$, although satisfaction is not a homogeneous and unproblematic phenomenon in relation to learning ${ }^{[6,7]}$. In comparing different learning approaches the students reported that they preferred the more familiar and traditional ${ }^{[8,9]}$. 
Simulation includes several phases, as the participants need to be prepared for the topic being played out (prebriefing) and to be familiar with the technology and equipment involved and the opportunities and limitations that are present (briefing). In the scenario, some participants perform actions while the rest of the group observe, whereas in the debriefing following immediately after the scenario, the faculty and the students reexamine what took place in the scenario, a reflective learning process to promote the development of clinical reasoning and judgment skills in an active learning environment ${ }^{\text {[10-13] }}$. Although debriefing is considered to be essential for achieving learning in simulation, there is still a lack of knowledge about how to perform this phase ${ }^{[11,14-16]}$. For achieving simulation competency, it is vital that the students are familiar with and accustomed to the principles and strategies used ${ }^{[17]}$, which is also essential for a positive learning outcome ${ }^{[18-21]}$. This also includes in debriefing the need to know the principles of the method, being able to problem-solve the topic, and a willingness to be involved and actively participate.

\section{Background}

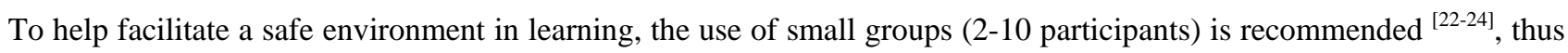
making HPS a resource-intensive method ${ }^{[19,24,25]}$. It may therefor pose a major challenge in that the volume of students at the bachelor's level is high, so as a result the students are only infrequently exposed to HPS.

Accommodations to professional requirements as a nurse require developing the individual ability and courage to argue, to speak up and to deal with one's own stress and anxiety, and the faculty should assist the student in such personal development ${ }^{[26]}$. In enhancing patient safety, the ability to identify situational and personal factors associated with the risk of error is of great importance, as the students need to understand how they can learn from errors ${ }^{[5]}$. The use of large groups could contribute to a more frequent exposure and prepare the students for realistic clinical situations. Successful learning in large groups of medical students has been reported ${ }^{[27]}$, but it is important to take into consideration that experiences cannot be directly transferred from one discipline to another ${ }^{[14,28,29]}$. In the implementation of human patient simulation, and to help facilitate for learning, there is a need for research on how nursing students experience the debriefing conducted under different conditions. The purpose of the present study was to describe nursing students' experiences of the debriefing conducted in small and large groups through the use of a qualitative descriptive approach.

\section{Method}

\subsection{Setting and participants}

The study was implemented in the autumn of 2011 in a simulation centre at a university college in Norway. The informants conducted their second year of the three-year bachelor nursing study, and had prior experience with HPS. In the present study, they participated in HPS as part of their usual programme focusing on a patient suffering from cardiac failure. They attended either in two large- (38 and 50) or in six small groups (8 to 11). The rationale for the use of such large groups was to obtain information about the learning experiences under conditions in which HPS may provide an alternative for the typical lecture-style education. Except for the group size, they were provided equal conditions such as the same teachers, available time, terms and location. Oral and written information about the study was given from the first author in connection with HPS. Further recruitment was conducted by electronic reminders, and by the fact that the students conducted their medical, surgical or psychiatric clinical studies at the actual time of the interviews, by the responsible teachers. A convenience sample of 20 informants was requested. Out of 124 students 22 signed up, although two dropped out because of illness on the actual day, hence resulting in 20 participants (19 women and one man). Twelve informants represented the large groups, while eight represented the small ones, but not necessarily from the same group during the HPS. Moreover, they ranged in age from 20 to 44 years (median 22). 


\subsection{Data collection}

Five focus group interviews ${ }^{[30]}$ were conducted on campus or in the clinic approximately three weeks after the HPS. The groups consisted of two to six informants determined by how many signed up from the same clinical practice, and information about the study, the aim and a map showing the simulation phases schematic (prebriefing - briefing - scenario - debriefing) was introduced to the students to emphasize the focus on debriefing. An open-ended question was used: "Can you please tell how you experienced the debriefing? whereas follow-up questions such as: Can you please tell me more about/give an example of/ explain... were also used in an attempt to promote a common understanding of meaning ${ }^{[30,31]}$ ). An observer (not included in the research group) followed all the interviews and supported the moderator (the first author) by including input from all the participants ${ }^{[32,33]}$. The interviews took the form of a dialogue, lasted from 50 to 60 minutes and were conducted during a period of eight days, and digital recording was used and transcribed verbatim.

\subsection{Data analysis}

A manifest content analysis ${ }^{[31]}$ consisting of three phases was used, including going forward and back as a process "by hand". In the preparation phase, the unit of analysis was selected on the basis of the aim of the study, and making sense of the data and the whole was done by listening to the interviews and repeatedly reading the transcript. In the organizing phase, open coding was performed by freely writing notes in coding sheets that represented all aspects of the meanings in the text. The notes that belonged together were collected into groups, and those that were similar were reduced into sub-categories. Generated from similar sub-categories, the generic categories emerged. An abstraction into a main category to represent a general description of the content was done, and in the reporting phase, an overview of the categories labelled by the characteristic words was used to show the process and the findings.

\subsection{Ethics}

Implementation of the study was approved by the Norwegian Social Science Data Services (NSD) and by the university college, and ethical guidelines for nursing research ${ }^{[34]}$ were followed. Confidentiality and voluntariness was emphasized in the written and oral information, and that the individual answers would have no impact on them as students or in their study programme. The informants signed a written consent form. None of the researchers took part in the implementation of the simulation.

\subsection{Trustworthiness}

To ensure trustworthiness, the three criteria of credibility, dependability and transferability were used ${ }^{[35]}$. Credibility was established by the participants to represent both small and large groups, and in addition the performers and the observers in the scenario. Concerning age there was variation, but with regard to gender only females attended with the exception of one man. A pilot interview that was not included in the study was conducted to test the interview question and to help the interviewer to be comfortable in the situation. Credibility was increased by the research group, representing a variation in competency with regard to simulation experience and knowledge, thereby reducing the risk of the findings to be influenced by preconceived opinions. Authentic citations were used to increase the trustworthiness, and to show on which data the categories were formulated. The statements, sub- and generic-categories were discussed in the research group until a consensus was reached. With regard to dependability the same introduction and open-ended questions were used in all groups. Concerning transferability, the results may have relevance when simulation is used, especially in relation to nurse education.

\section{Results}

The debriefing was perceived as the most important phase in HPS by being a forum for learning and discussion, which possessed different viewpoints and suggestions to problem solving. However, a recurrent experience was that the informants felt that they had been put in a vulnerable position, characterized by a high risk of disgracing themselves and ending up in a stressful and intrusive situation. Reluctance to exposure was particularly found in the large groups. This fear 
was connected with being the one to perform in the scenario, but was also emphasized as a threat in debriefing by the chance of revealing a lack of knowledge in questioning, in comments and in public humor. Although acclaiming the teacher's abilities in creating a good learning environment and conducting the facilitation, they reported to have used focus and energy to avoid being exposed. The main category, the fear of being put into the discomfort zone, was generated from the three generic- and six sub-categories (see Table 1).

Table 1. Sub-categories, generic categories and main category

\begin{tabular}{|c|c|c|c|c|c|c|}
\hline Main category & \multicolumn{6}{|c|}{ The fear of being put into the discomfort zone } \\
\hline $\begin{array}{l}\text { Generic } \\
\text { categories }\end{array}$ & \multicolumn{2}{|c|}{ Experienced as transferable learning } & \multicolumn{2}{|c|}{$\begin{array}{l}\text { Activity is a prerequisite for } \\
\text { learning }\end{array}$} & \multicolumn{2}{|c|}{$\begin{array}{l}\text { Predictability and preparedness } \\
\text { are essential for learning }\end{array}$} \\
\hline $\begin{array}{l}\text { Sub } \\
\text { categories }\end{array}$ & $\begin{array}{l}\text { To facilitate } \\
\text { the digestion } \\
\text { of knowledge }\end{array}$ & $\begin{array}{l}\text { To be relevant for } \\
\text { professional } \\
\text { requirements }\end{array}$ & $\begin{array}{l}\text { To ensure safety } \\
\text { and security }\end{array}$ & $\begin{array}{l}\text { To be } \\
\text { challenged }\end{array}$ & $\begin{array}{l}\text { To be familiar } \\
\text { with the } \\
\text { facilitation }\end{array}$ & $\begin{array}{l}\text { To possess } \\
\text { knowledge of } \\
\text { the topic }\end{array}$ \\
\hline
\end{tabular}

\subsection{Experienced as transferable learning}

This generic category included the findings that showed debriefing to have given ample opportunities for transferable learning to both the clinical practice and theoretical exams, emerging from two sub-categories incorporating statements about debriefing: To facilitate the digestion of knowledge, and To be relevant for professional requirements.

\subsubsection{To facilitate the digestion of knowledge}

Debriefing was considered as effective learning by offering the opportunity to understand difficult theoretical knowledge connected to a performed situation. By being given immediate feedback, time and the chance to think, reflect and discuss several solutions, the knowledge was understood. Questions and confusion were clarified and supported the learning process, with the informants asserting that in order to further learning, the discussion had to end up with a conclusion, a straight answer stated or quality approved by the teacher. One said: "I learned a whole lot in a short time” (Int.2).

To have to think holistically in problem solving, to be forced to explain and to justify their suggestions and solutions to the issues was experienced as essential for learning. It helped them to remember, and as one stated: "Saying it loud to yourself and in a group is a good way to learn. Just the act of saying it" (Int.2). The experience of learning different things by being the performer in the scenario (to cope with stress) or the observer (to learn the topic) was revealed. Several pointed out that it was the observers who achieved the best learning, insofar as that being the performer, the level of stress and the preoccupation with their own actions made them forget what had happened in the scenario and caused a lack of focus in debriefing.

\subsubsection{To be relevant for professional requirements}

It was perceived that debriefing made them more aware and conscious of the focus on their own and others' competency, which was considered to be important for a future nurse working in teams. Debriefing was a suitable way to acquire training in justifying actions, attitudes and options conceived as an important part of professionalism. There was a realization that the safety and security possessed in the small groups did not provide sufficient challenges for future required competence. As one stated: “To dare to give your opinion when you're in a group and stand by it and talk things over, that's important" (Int.2). Nevertheless, the learning strategies were shown to have an impact to such an extent that it caused doubts about their suitability for the profession, expressed as: “Am I really suited for this?” (Int.3)

\subsection{Activity is a prerequisite for learning}

This generic category stated activities such as asking and answering questions, participating in discussions, formulating reflections and sharing knowledge as a prerequisite for learning. It emerged out of statements concerning the required conditions for active participation, as collected in the sub-categories: To ensure safety and security, and To be challenged. 


\subsubsection{To ensure safety and security}

Irrespective of the group size, the experience of a fear of disgrace or failure was revealed. However, in the small groups, the chance to actively participate could be taken by a few witnesses. Safety and security was safeguarded to such an extent that the debriefing was considered as a student-active method. In the large groups it was found to be more like ordinary lectures, in that the students asked questions and the teacher answered them. The fear of failure or disclosure by not having sufficient or adequate knowledge in the presence of many unknown fellow students hampered learning, and quite a bit of energy and attention was used to hide and avoid being the one to be exposed. To take the chance to disclose oneself was not an easy step to take, which was expressed as follows: “...I was really scared of saying something wrong, so I can’t say I was particularly active in the debriefing. When I said something I was terribly nervous it was wrong, and when it was wrong, it was awful” (Int.2).

In the large groups, the informants experienced that they were individually exposed and abandoned, and they felt small. Attending the small groups was different; the experiences of group identity, being a member of a team and shared responsibility in problem solving were all revealed. One stated: “I think it really helped that I was in the group I'm normally with, and I dared to say whatever I was thinking because I wasn't afraid of saying something wrong” (Int.2). Proposals about how to establish security, confidence and the habituation of individual exposure recommended the use of small groups at the start and then successively merging them into larger ones.

\subsubsection{To be challenged}

The informants acknowledge the need for some pressure and to be individually challenged in active participation as being important in learning. One expressed this as follows: "I think it (pressure) is an important thing. You learn when you must...now you have to reckon on being asked directly instead of sitting in a room with lots of others and just hiding away" (Int.4). The teacher's open-ended questions and breaking down existing viewpoints to make the students think and reflect was appreciated. The teacher's abilities in professional knowledge were of importance, but equally important were the interest and dedication for the students' learning process. It was much appreciated that they were given encouragement and that failure was not in focus. The feeling of mastery occurred when the informants stretched beyond their borders and received constructive feedback, as expressed by one: “...'cause you sort of straightened your back and stood up for your own opinion, that's how I felt it” (Int.3).

\subsection{Predictability and preparedness are essential for learning}

This generic category stated the need for habituation to active learning strategies and the requirement for individual preparedness for the topic being played out. It emerged from two-sub categories: To be familiar with the facilitation and To possess knowledge of the topic.

\subsubsection{To be familiar with the facilitation}

The learning strategies used were experienced as unfamiliar by the informants who had only infrequently been exposed to HPS. Differences in ways of conducting facilitation that were dependent on the responsible teacher made the informants unsure about what was expected. More information and knowledge about the HPS phases, the principles and the requirements involved was requested. The lack of similar learning strategies used in the programme in general was pointed out as an important factor for unfamiliarity and insecurity, with one stating: "We are not encouraged so much to think for ourselves and express our own opinions” (Int.1).

In the large groups, the students automatically assumed a passive role. A request arose that HPS and similar learning strategies should be introduced at an early stage and frequently used in the programme. One said: “.that we get to know about it (the learning method) as early as possible and learn how to involve right from the start” (Int.4). To be familiar with the teacher's way of including and leading the group, as well as expectations, humour and the way of asking, responding and giving feedback, was all experienced as being of importance. 


\subsubsection{To possess knowledge of the topic}

It was emphasized that possessing a solid knowledge of the topic being played out was essential for achieving learning in debriefing, with one saying: "I was pretty well prepared beforehand and so I could join in discussions with the teacher and fellow-students, so personally I got a great deal out of it” (Int.2). According to the informants, preparedness for the topic should be a mutual duty among the students. Although this should be each student's responsibility, the need for some kind of requirement and check that the individual was actually prepared was acknowledged.

\section{Discussion}

A recurrent finding in all the interviews coincidental with other studies ${ }^{[16,36,37]}$ was the informants experiencing simulation and especially debriefing, as highly relevant to facilitating effective learning. Their concerns and discussions revolved around the learning conditions and what in the literature is called a "lack of simulation competency" [17]. Irrespective of group size, they experienced the learning strategies used as unfamiliar, stressful and intrusive and breaking the common perception of the teacher's and student's roles in learning in their education. Their reluctance to exposure was related to their socialized student role, which was generally described as passive and receiving without having to leave what is featured as the comfort zone, characterized by not having to face any particularly new challenges ${ }^{[38,39]}$.

The findings supported that learning requires to a certain degree some pressure to take risks to leave one's comfort zone, and the acknowledgement that the learning strategies used depend on involvement and activity ${ }^{[14,28]}$. However, the informants who attended the large groups described having used strategies such as withdrawal, retreating during group sessions, avoiding eye contact, being uncooperative and being non-communicative in order to prevent being put in the spotlight during the debriefing. These strategies are known as physical and behavioural manifestations of anxiety ${ }^{[40]}$. Though some level of anxiety is positive in that it mobilizes for action, is dependent on the person's ability to cope with such feelings. If the learner perceives the situation as posing challenges that exceed the learner's ability to cope, and causes a high level of stress and anxiety, it will impede effective learning ${ }^{[17,41]}$, known as entering the discomfort zone ${ }^{\text {[39] }}$, or also called the panic zone ${ }^{[38]}$. By not meeting their own or others' expectations, and the judgment of many unknown fellow students, the perceived risk of disclosure caused energy, focus and attention to be used on avoiding being exposed, thereby affecting the methodological success in learning adversity. Such a shame and blame attitude is known to be a barrier for success in simulation ${ }^{[14]}$ and for learning in general ${ }^{[39,42]}$.

The informants who attended the small groups also reported having experienced the debriefing as intrusive and stressful, but the risk of disclosure and failure and the consequences were all perceived as manageable. Chances could be taken and tackled when there were few witnesses present. This is referred to as entering the learning zone ${ }^{\text {[3] }}$, which is used as a concept for a heightened learning experience. It means to leave one's comfort zone and be in a state of developing and acquiring new knowledge. This zone is conceived as the area that overlaps the edge of the comfort- and discomfort zone, and known as the (dis)comfort zone ${ }^{[39]}$, in which entering means to perceive a sense of risk and challenge that causes emotional and physical responses to novel tasks.

However, the findings also showed a realization that the small and safe groups did not possess sufficient challenges for professional requirements as a nurse. The need to show individual courage, and an ability to justify and account for their own actions under highly stressed conditions, were acknowledged as an important part of professional education. Debriefing in large groups was perceived as an excellent learning method for such training and personal development, which also includes concerns with the sensitive and contentious issues of values and the ideals of students ${ }^{[43,44]}$. The findings showed the importance that the faculty has to acknowledge that such learning situations might have a strong impact on the individual, and feelings of success or failure can affect the perception of suitability for the profession.

The findings supported that the teachers' abilities in facilitating are crucial ${ }^{[20,45]}$. The educator's role is to clarify what kind of communities the students should learn for and to recognize that the perception of risk and tolerance for anxiety is individual ${ }^{[40]}$. In building a community for learning, the students need to know/develop/build understanding, rules and 
agreement on how to communicate, the motivation for communication, the value of discussion and diverse viewpoints ${ }^{[14,46]}$. Both the students and teachers alike must learn and understand "school talk" - the reason for- and principles in the learning strategies, why use follow-up questions, why we ask for a deeper explanation and how to reflect ${ }^{[17,39]}$. Without such agreements, the students might feel threatened and ridiculed by the teachers' provocative questions. The experiences of the learning community and consciousness in localization of their individual learning zone are important for the students' learning, but also influence how the students will be part of building communities in the future ${ }^{[46]}$.

The classroom culture was referred to as an important factor that affected the level of activity in debriefing, which was described as generally being tacit when attending large groups already established from the start. A tacit agreement was established; some had taken a responding role, while the others were silent. In attending small groups, the activity increased among all. In addition, some informants referred to previous negative experiences in exposure in large groups as a reason for their reluctance to become involved, and these experiences created mistrust. This finding highlighted that it is urgent that there is a common consciousness among the educators of their collective responsibility and the codes of ethical practice for the learning community ${ }^{[7]}$, as learning depends on solid foundations and strong relationships of trust and support between educator and learner and between learners ${ }^{[38,47]}$.

\section{Limitations}

The interviews were conducted approximately three weeks after the implementation of the HPS. The distance in time and the informants' present occupation in the clinical practice may have influenced to what degree they recalled their experiences. On the other hand, the intermediate time enabled the informants to assess their learning experiences from HPS and its relevancy for the clinic. The findings that emerged from focus-group interviews could be affected by the informants influencing each other's opinions ${ }^{[32]}$. However, the benefit is that the groups have a lively collective interaction ${ }^{[30]}$, which in the present study seemed to encourage the individual to express experiences and feelings not obvious to be expected or "correct" for the setting. A limitation was that by coincidence the number of participants in two groups turned out to be below the recommended size ${ }^{[30]}$. Nonetheless, the major factor for the recommendation is to ensure enough participants to contribute to wealth and a variety of viewpoints ${ }^{[30,48]}$. In the present study, the moderator's activity and the findings were quite coincidental independent of the group size. A convenience sample might be biased by the informants not representing variation ${ }^{[32]}$, and with regard to gender only one man participated, although this primarly reflects the gender balance in nurse education. The findings were influenced by the informants' description of their class culture as silent, their being unfamiliar with the method and not actively participating in large groups, conditions which may differ between programmes and classes.

\section{Conclusion}

In the use of human patient simulation, debriefing is a crucial phase for learning, with small groups providing the best learning conditions insofar as ensuring safety and security. By contrast, participation in large groups provides learning situations that are relevant and important in order to achieve personal development and to accommodate professional requirements as a nurse. Active participation is essential in simulation competency and as a prerequisite for learning. This competency is not developed isolated in conjunction with simulation, but the familiarity and habituation to the learning strategies must be an integrated part of the student role in the nursing programme in general. To achieve competency depends on a systematic building of a learning community, including a consciousness and habituation to learning in general as a heightened learning experience out of the students' comfort zone. There is a need for further research about how to facilitate learning in debriefing and how to develop students' competency in active learning strategies as used in HPS.

\section{Relevance to clinical practice}

The debriefing phase in human patient simulation helps in facilitating the transfer of theoretical knowledge into clinical situations. The faculty needs to support the students in being conscious of- and habituated to learning as a heightened 
learning experience out of their comfort zone. This is important for their learning process, but also because competency in nursing care is often conducted under stressful conditions. During debriefing, the students can achieve awareness about the effective teamwork required for patient safety. Situational and personal factors associated with the risk of errors can be identified and analysed, and strategies to reduce errors can be discussed. Debriefing in large groups provides the opportunity for the individual to develop the courage to speak up, as well as to argue and justify their own priorities and solutions that accommodate the professional requirements for nurses.

\section{Acknowledgements}

We would like to thank the students for sharing their experiences and our colleagues Mari Bjerkvold, Haakon Soerum and Christer Eriksson for their support and expertise in the implementation of the scenarios.

\section{References}

[1] Kardong-Edgren, S., Willhaus, J., Bennett, D., \& Hayden, J. Results of the National Council of State Boards of Nursing National Simulation Survey: Part II. Clinical Simulation in Nursing. 2012; 8(4): e117-e123. http://dx.doi.org/10.1016/j.ecns.2012.01.003

[2] LaFond, C. M., \& Van Hulle Vincent, C. A critique of the National League for Nursing/Jeffries simulation framework. Journal of Advanced Nursing. 2012; 69(2): 465-480. http://dx10.1111/j.1365-2648.2012.06048.x

[3] McCaughey, C. S., \& Traynor, M. K. The role of simulation in nurse education. Nurse Education Today. 2010; 30(8): 827-832. http://dx10.1016/j.nedt.2010.03.005

[4] Cant, R. P., \& Cooper, S. J. Simulation-based learning in nurse education: systematic review. Journal of Advanced Nursing. 2010; 66(1): 3-15.

[5] WHO. WHO patient safety curriculum guide: Multi-professional edition. Available from: http://whqlibdoc.who.int/publications/2011/9789241501958_eng.pdf

[6] Davis, D. A., Mazmanian, P. E., Fordis, M., Van Harrison, R., Thorpe, K. E., \& Perrier, L. Accuracy of Physician Self-assessment Compared With Observed Measures of Competence. A Systematic Review. Journal of the American Medical Association. 2006; 296(9): 1094-1102. http://dx.doi.org/10.1001/jama.296.9.1094

[7] Schuck, S., Gordon, S., \& Buchanan, J. What are we missing here? Problematising wisdoms on teaching quality and professionalism in higher education. Teaching in Higher Education. 2008; 13(5): 537-547. http://dx.doi.org/10.1080/13562510802334772

[8] Tosterud, R., Hedelin, B., \& Hall-Lord, M. L. Nursing students’ perceptions of high- and low-fidelity simulation used as learning methods. Nurse Education in Practice. 2013; 13(4): 262-270. PMid:23454066 http://dx.doi.org/10.1016/j.nepr.2013.02.002

[9] Zulkosky, K. D. Simulation Use in the Classroom: Impact on Knowledge Acquisition, Satisfaction, and Self-Confidence. Clinical Simulation in Nursing. 2012; 8(1): e25-e33. http://dx10.1016/j.ecns.2010.06.003

[10] Dreifuerst, K. T. The Essentials of Debriefing in Simulation Learning: A Concept Analysis. Nursing Education Perspectives. 2009; 30(2): 109-114. http://dx.doi.org/10.1043/1536-5026-030.002.0109

[11] Fanning, R. M., \& Gaba, D. M. The role of debriefing in simulation-based learning. Simulation in Healthcare. 2007; 2(2): $115-125$. http://dx.doi.org/10.1097/SIH.0b013e3180315539

[12] Grabinger, R. S., \& Dunlap, J. C. Rich environments for active learning: A definition. Research in Learning Technology. 1995; 3(2).

[13] Lasater, K. High-fidelity simulation and the development of clinical judgment: Students' experiences. Journal of Nursing Education. 2007; 46(6): 269-276. PMid:17580739

[14] Dieckmann, P., Friis, S. M., Lippert, A., \& Østergaard, D. Goals, Success Factors, and Barriers for Simulation-Based Learning A Qualitative Interview Study in Health Care. Simulation \& Gaming. 2012; 43(5): 627-647. http://dx.doi.org/10.1177/1046878112439649

[15] McGaghie, W. C., Issenberg, S. B., Petrusa, E. R., \& Scalese, R. J. A critical review of simulation-based medical education research: 2003-2009. Medical Education. 2010; 44(1): 50-63. http://dx10.1111/j.1365-2923.2009.03547.x

[16] Shinnick, M. A., Woo, M., Horwich, T. B., \& Steadman, R. Debriefing: The Most Important Component in Simulation? Clinical Simulation in Nursing. 2011; 7(3): e105-e111. http://dx10.1016/j.ecns.2010.11.005

[17] Dieckmann, P. Simulation settings for learning in acute medical care. In P. Dieckmann (Ed.), Using simulations for education, training and research. 2009; 40-138. Lengerich: Pabst. 
[18] Henneman, E. A., Cunningham, H., Roche, J. P., \& Curnin, M. E. Human patient simulation: teaching students to provide safe care. Nurse educator. 2007; 32(5): 212-217. http://dx10.1097/01.NNE.0000289379.83512.fc

[19] Jeffries, P. R., \& Rogers, K. J. Theoretical Framework for Simulation Design. In P. R. Jeffries (Ed.), Simulation in nursing education: From conceptualization to evaluation. 2007; 21-33. New York: National League for Nursing.

[20] Keitel, A., Ringleb, M., Schwartges, I., Weik, U., Picker, O., Stockhorst, U., et al. Endocrine and psychological stress responses in a simulated emergency situation. Psychoneuroendocrinology. 2011; 36(1): 98-108. http://dx.doi.org/10.1016/j.psyneuen.2010.06.011

[21] Savoldelli, G. L., Naik, V. N., Hamstra, S. J., \& Morgan, P. J. Barriers to use of simulation-based education. Canadian Journal of Anesthesia. 2005; 52(9): 944-950. http://dx10.1007/BF03022056

[22] Alinier, G., Hunt, B., Gordon, R., \& Harwood, C. Effectiveness of intermediate-fidelity simulation training technology in undergraduate nursing education. Journal of Advanced Nursing. 2006; 54(3): 359-369. http://dx.doi.org/10.1111/j.1365-2648.2006.03810.x

[23] Childress, R. M., Jefferies, P. R., \& Dixon, C. F. Using collaboration to enhance the effectiveness of simulated learning in nursing education. In P. R. Jeffries (Ed.), Simulation in nursing education: from conceptualization to evaluation. New York: Natl League for nursing. 2007; 123-135.

[24] Sinclair, B., \& Ferguson, K. Integrating simulated teaching/learning strategies in undergraduate nursing education. International Journal of Nursing Education Scholarship. 2009; 6(1): 1-11. PMid:19341357 http://dx.doi.org/10.2202/1548-923X.1676

[25] Mikkelsen, J., Reime, M. H., \& Harris, A. K. Nursing students' learning of managing cross-infections - Scenario-based simulation training versus study groups. Nurse Education Today. 2008; 28(6): 664-671. PMid:18164104 http://dx.doi.org/10.1016/j.nedt.2007.11.003

[26] Moscaritolo, L., M. Interventional Strategies to Decrease Nursing Student Anxiety in the Clinical Learning Environment. Journal of Nursing Education. 2009; 48(1): 17. PMid:19227751 http://dx.doi.org/10.3928/01484834-20090101-08

[27] Heitz, C., Brown, A., Johnson, J. E., \& Fitch, M. T. Large group high-fidelity simulation enhances medical student learning. Medical teacher. 2009; 31(5): e206-e210. PMid:19811125 http://dx.doi.org/10.1080/01421590802637990

[28] Aldrich, C. 9 Paradoxes of Educational Simulations. T+D. 2006; 60(5): 49-52.

[29] Jeffries, P. R. Designing Simulations for Nursing Education. Annual Review of Nursing Education. 2006; 4: 161-165,167-171,173-XII.

[30] Kvale, S., \& Brinkmann, S. Interviews: learning the craft of qualitative research interviewing. Los Angeles, Calif. 2009: Sage.

[31] Elo, S., \& Kyngäs, H. The qualitative content analysis process. Journal of advanced nursing. 2008; 62(1): 107-115. PMid:18352969 http://dx.doi.org/10.1111/j.1365-2648.2007.04569.x

[32] Polit, D. F., \& Beck, C. T. Nursing research: generating and assessing evidence for nursing practice. Philadelphia, Pa.: Wolters Kluwer Health, 2012.

[33] Wibeck, V., Dahlgren, M. A., \& Öberg, G. Learning in focus groups an analytical dimension for enhancing focus group research. Qualitative Research. 2007; 7(2): 249-267. http://dx.doi.org/10.1177/1468794107076023

[34] Northern Nurses' Federation. Ethical guidelines for nursing research in the Nordic countries, 2003. Available from: http://www.sykepleien.no/ikbViewer/Content/337889/SSNs\%20etiske\%20retningslinjer.pdf

[35] Graneheim, U. H., \& Lundman, B. Qualitative content analysis in nursing research: concepts, procedures and measures to achieve trustworthiness. Nurse education today. 2004; 24(2): 105-112. PMid:14769454 http://dx.doi.org/10.1016/j.nedt.2003.10.001

[36] Darcy Mahoney, A. E., Hancock, L., Iorianni-Cimbak, A., \& Curley, M. A. Using high-fidelity simulation to bridge clinical and classroom learning in undergraduate pediatric nursing. Nurse Education Today. 2012; 33(6): 648-654. http://dx.doi.org/10.1016/j.nedt.2012.01.005

[37] Gore, T., Hunt, C. W., Parker, F., \& Raines, K. H. The Effects of Simulated Clinical Experiences on Anxiety: Nursing Students' Perspectives. Clinical Simulation in Nursing. 2010; 7(5): e1-e6.

[38] Brown, M. Comfort zone: Model or metaphor. Australian Journal of Outdoor Education. 2008; 12(1): 3-12.

[39] Eldridge, D. B., Hu, Y., \& Tuten, J. A. Teaching and learning in the (dis) comfort zone: A guide for new teachers and literacy coaches: Palgrave Macmillan; 2010.

[40] Davis-Berman, J., \& Berman, D. Risk and anxiety in adventure programming. Journal of Experiential Education. 2002; 25(2): 305-310. http://dx.doi.org/10.1177/105382590202500209

[41] Ganley, B. J., \& Linnard-Palmer, L. Academic Safety during Nursing Simulation: Perceptions of Nursing Students and Faculty. Clinical Simulation in Nursing. 2012; 8(2): e49-e57. http://dx.doi.org/10.1016/j.ecns.2010.06.004

[42] Anderson, L. W. Upper elementary grades bear the brunt of accountability. Science. 2009; 5(5.5): 8.1.

[43] Carper, B. A. Fundamental Patterns of Knowing in Nursing. In W. K. Cody (Ed.), Philosophical and theoretical perspectives for advanced nursing practice. 2013; 23 -33. Burlington, Mass.: Jones and Bartlett Learning. 
[44] McGettrick, B. Towards a framework of professional teaching standards: a response to the consultative document "Towards a Framework for Professional Teaching Standards”. Bristol: Higher Education Academy, Education Subject Centre, ESCalate University of Bristol, Graduate School of Education; 2005.

[45] Cantrell, M. A. The Importance of Debriefing in Clinical Simulations. Clinical Simulation in Nursing. 2008 ; 4(2): e19-e23. http://dx10.1016/j.ecns.2008.06.006

[46] Renshaw, P. D. Community and learning: Contradictions, dilemmas and prospects. Discourse: studies in the cultural politics of education. 2003; 24(3): 355-370. http://dx10.1080/0159630032000172533

[47] Vella, J. Learning to listen, learning to teach: The power of dialogue in educating adults. San Francisco: Jossey-Bass; 2002.

[48] Morgan, D. L. Focus groups as qualitative research. 1997; 16: Sage. 